\title{
The Concept of Modern Ankle Joint Arthrodesis in Posttraumatic Crusarthrosis, Grade III-IV
}

DOI: $10.17691 /$ stm2016.8.3.07

Received September 22, 2015

R.O. Gorbatov, Head of the Laboratory of Additive Technologies";

V.V. Gorin, Traumatologist-Orthodedist ${ }^{1}$;

D.V. Pavloy, MD, PhD, Head of Traumatological and Orthopedic Department';

E.E. Malyshev, MD, PhD, Associate Professor, Department of Traumatology, Orthopedics and Military Field Surgery named after M.V. Kolokoltsev²

Privolzhsky Federal Research Medical Center, Ministry of Health of the Russian Federation, 18 Verkhne-Volzhskaya naberezhnaya, Nizhny Novgorod, 603155, Russian Federation;

2Nizhny Novgorod State Medical Academy, 10/1 Minin and Pozharsky Square, Nizhny Novgorod, 603005, Russian Federation

The aim of the investigation was to work out a concept of modern arthrodesis of the ankle joint in posttraumatic crusarthrosis, grade III-IV, using innovative fixing implants.

Materials and Methods. The results of treating 53 patients covering the period from 1 to 15 years after 56 operations of arthrodesis, performed for posttraumatic crusarthrosis, grade III-IV (according to Kellgren and Lawrence classification), have been analyzes. The conclusions were based on the data of radiographic, clinical examination and the scoring according to the international rating scale AOFAS. Arthrodesis was performed using state-of-the-art fixing implants: with the help of the screws, retrograde intramedullary HAN rod, Ilizarov apparatus for external fixation, wires.

Results. In the majority of patients (41\%) the main cause of developing posttraumatic crusarthrosis of grade III-IV was unrepaired intraarticular dislocation of the ankle fragments and a large fragment (more than 1/3) of the posterior tibia margin. The best results, i.e. fewer ligamentous ankylosis (32\%) and the greatest number of good (39\%) and satisfied $(54 \%)$ results according to AOFAS scale were obtained when crossed screws were used in arthrodesis. It was estimated, that the assessment of clinical and functional signs according to the international scale AOFAS does not reflects the most vital spectrum of life activity indices of patients, therefore, it has been suggested to use additionally individualized indices characterizing the quality of life of patients of various professions, levels of every-day activity and psychological motivation to adequate rehabilitation. Unsatisfied radiographic findings did not always corresponded to the poor clinical results. In 56\% of patients with ligamentous ankylosis the result according to AOFAS was good or satisfactory (slight pains in prolonged walking, moving without additional supporting means, absence of evident limping).

Conclusion. The worked out concept of modern arthrodesis is as follows: 1) the choice of ankle arthrodesis method and the type of a fixing implant must depend not only on the type of deformation, but on the patient's age, gender traits, diseases contributing to the development of unfavorable treatment results; 2) the best clinical and functional results are connected with the method of fixation providing primary stability, and with regenerative and adaptive capabilities of patients in diverse age groups; 3 ) the most optimal state-of-the-art implants for arthrodesis are crossed screws for fixation, providing the greatest strength and good primary compression, if there is no marked disorder of blood supply of the articular bones and radical removal of the cartilaginous tissue.

Key words: posttraumatic arthrosis of the ankle joint; ankle joint arthrodesis; AOFAS scale; screws; HAN rod; wires; Ilizarov apparatus.

Injuries of the ankle joint are the most common traumas of the locomotor apparatus and amount to $12-24 \%$ of all bone injuries, reaching $40-60 \%$ for the ankle bone fractures [1, 2]. Despite a great variety of surgical and conservative methods of treatment of such lesions, the number of unsatisfied results amounts to $7-38 \%$ [3-5], and in heavy pronation fractures to $20-40 \%$ [6]. Traumas in this region occur in 60-70\% of the working age population. Posttraumatic arthrosis of the ankle joint develops in $60 \%$ of cases $[7,8]$. Invalidization in such pathology is $8.8-46.0 \%$ [3-5]. The main causes of arthrosis are: unrepaired subluxation of the foot or chronic dislocation fracture of the ankle joint, unsatisfactory reposition of the fragments after ankle fractures, chronic instability caused by the injury of the ankle joint ligamentous apparatus [9-12]. Irreversibility of the degenerative and dystrophic process, a high percentage of patient disability necessitate developing the concept of operative treatment of people with posttraumatic deforming crusarthrosis [4, 5, 13]. A variety of conservative and operative methods of treating the pathology are known. But one of the most common and

For contacts: Roman O. Gorbatov, e-mail: gorbatov.ro@yandex.ru 
sometimes the only possible method of treating patients with posttraumatic ankle joint arthrosis of grades IIIIV is arthrodesis, which preserves support ability and arrests a pain syndrome $[14,15]$. Arthrodesis with the application of state-of-the-art fixators and technologies enabled many patients to maintain their usual life style: to ride a bicycle, drive a car, go in for sports, and so on, though previously it was considered impossible [16-20].

There are diverse methods of performing arthrodesis: open or closed, with or without using bone auto- or alloplasty, under visual and roentgenocontrol, with the help of computer navigation or arthroscopic tools. The following fixators are used for this procedure: screws, wires, plates, plaster bandages, intramedullary rods, apparatuses for external fixation and their combinations. Such great number of methods and fixators is required to meet the variety of individual indications for each patient depending on his comorbid condition, type and kind of deformation, surgeon's skills and experience in performing this or that procedure, basic operating-room equipment, and so on.

Various kinds of arthrodesis and implants have their advantages and drawbacks [19, 21-24]. Wires, used as fixators in arthrodesis of ankle joints do not provide compression in the zone of the resected joint surfaces and must be applied with a supplementary immobilization by a plaster bandage. There exists a risk of developing pyoinflammatory processes. Screws provide greater fixation stability than wires. There are techniques, where 2 or 3 screws, introduced in different planes, are applied [20, 25-27]. Intramedullary rods allow the surgeon to perform the operation technologically according to a standard protocol, make compression in the postoperative period possible, but inevitably result in blockage of the subtalar joint. A retrograde intramedullary HAN rod (Synthes, Switzerland) and a similar A3 fixator (Small Bone Innovation, USA), differing from the first one only by an additional distal bending and absence of the second calcaneal screw, are most commonly used [28, 29]. Some authors consider a retrograde intramedullary rod to be not sufficiently stable and recommend reinforcing the zone of arthrodesis by a lateral L-shaped plate [30, 31].

Arthroscopic arthrodesis impairs the blood supply of the talus and tibia to a lesser extent, diminishes the damage of the surrounding soft tissues, leading to shorter periods of bone ankylosis formation. The method does not imply ankle osteotomy and, as a rule, is used only in small angle deformity (varus or valgus up to $5^{\circ}$ ) [32-34]. Arthrodesis, performed with apparatuses of external fixation (designed by Grishin, llizarov, or Calandruccio II technique), allows the surgeons to achieve formation of bone ankylosis with the resection of the joint surface or without it, to repair heavy deformity and provide compression in the postoperative period. However, there exists a high risk of inflammation at the site of wire insertion, weir cutting through, especially in osteoporosis, which is noted in the majority of patients with crusarthrosis, besides carrying the apparatus for a long period of time is not comfortable for the patients [35-38].

Some authors report unsatisfactory outcomes of arthrodesis in patients suffering from obesity, diabetes mellitus, rheumatoid arthritis, impaired blood supply of the distal part of the lower limb [39-42].

The aim of the investigation was to work out a concept of modern arthrodesis of the ankle joint in posttraumatic crusarthrosis, grade III-IV, using innovative fixing implants.

Materials and Methods. The work is based on the data of clinical and radiographic examinations of 53 patients, which underwent 56 operations of ankle joint arthrodesis for posttraumatic crusarthrosis, grade IIIIV, using state-of-the-art technologies and fixators. The operations were carried on in Nizhny Novgorod Research Institute of Traumatology and Orthopedics in the period from 2000 to 2014. Scoring according to an international rating scale AOFAS was additionally carried out in 31 patients. The results of 1-15-year follow up have been assessed.

The study complies with the Declaration of Helsinki (the Declaration was passed in Helsinki, Finland, June, 1964, and revised in October, 2000, Edinburg, Scotland) and was performed following approval by the Ethics Committee of Privolzhsky Federal Research Center. Written informed consent was obtained from every patient.

Of 53 patients there were 27 females and 26 males at the age from 27 to 78 years (the average age $51.0 \pm 5.2$ years) participating in the study. The distribution of patients in accordance with AO/ASIF classification, the type of trauma and methods of treatment are presented in Table 1.

The main reasons of developing posttraumatic crusarthrosis, grade III-IV, were as follows:

1) unrepaired ligamentous apparatus of the ankle joint (rupture of the lateral and deltoid ligaments, instability of the distal fibiotibular syndesmosis), which led to chronic traumatization and degenerative changes of the cartilaginous surfaces in $9(17 \%)$ patients;

2) unrepaired intraarticular dislocation of the ankle fragments over $2 \mathrm{~mm}$ and a large fragment (more than $1 / 3$ ) of the posterior tibia margin in $22(41 \%)$ patients;

3 ) extensive posttraumatic injury of the ankle joint surfaces and mainly the talus, which resulted in the development of crusarthrosis despite the anatomic reposition of the bone fragments and stable fixation in 12 (23\%) patients;

4) multifragmental character of the fracture in 10 (19\%) patients.

The risk factor of unsatisfied outcomes was an unfavorable comorbid background: an over mass in $38 \%$ (BMI 25.0-29.9); obesity, stage I, in 17\% (BMI 30.034.9); obesity, stage II, in 15\% (BMI 35.0-39.9); morbid 
Table 1

Characteristic of patients with crusarthrosis depending on the type of trauma and methods of treatment

\begin{tabular}{llc}
\hline \multicolumn{1}{c}{$\begin{array}{c}\text { The type of ankle } \\
\text { joint trauma according } \\
\text { to AO/ASIF classification }\end{array}$} & \multicolumn{1}{c}{ Treatment method } & $\begin{array}{c}\text { Number } \\
\text { of patients }\end{array}$ \\
\hline B2 and C2 & $\begin{array}{l}\text { Closed reposition, plaster immobilization } \\
\text { Osteosynthesis by llizarov apparatus }\end{array}$ & 6 \\
\hline & Osteosynthesis by a plate and screws using AO method & 9 \\
\hline & Osteosynthesis by wires & 1 \\
\hline B3 & Closed reposition, plaster immobilization & 4 \\
\hline & Osteosynthesis by a plate and screws using AO method & 2 \\
\hline & Osteosynthesis by llizarov apparatus & 1 \\
\hline C3 & $\begin{array}{l}\text { Osteosynthesis of the lateral malleolus by a screw and wire, } \\
\text { fixation of fibiotibular syndesmosis by a positioning screw }\end{array}$ & 1 \\
\hline Injury of the ankle ligamentous & Closed reposition, plaster immobilization up to 2 weeks & 3 \\
\hline apparatus & Did not receive specialized treatment & 6 \\
\hline $\begin{array}{l}\text { Fracture of the ankles, type B }+ \\
\text { fractute of the talus }\end{array}$ & Closed reposition, plaster immobilization & 1 \\
\hline $\begin{array}{l}\text { Fracture of the ankles, type B }+ \\
\text { dislocation fracture of the talus }\end{array}$ & Osteosynthesis by llizarov apparatus & 1 \\
\hline Fracture of the talus & Closed reposition, wire fixation, plaster immobilization & 1 \\
\hline & Closed reposition, plaster immobilization & 1 \\
\hline & $\begin{array}{l}\text { Open reposition, osteosynthesis by a screw, plaster } \\
\text { immobilization }\end{array}$ & 1 \\
\hline
\end{tabular}

Table 2

Description of arthrodesis $(n=56)$ performed with various approaches and fixators

\begin{tabular}{|c|c|c|}
\hline $\begin{array}{l}\text { Type } \\
\text { of fixator }\end{array}$ & $\begin{array}{l}\text { Approach, additional notes } \\
\text { on the operation }\end{array}$ & $\begin{array}{c}\text { Quantity } \\
\text { of arthrodeses } \\
\text { (abs. number/\%) }\end{array}$ \\
\hline \multirow[t]{4}{*}{ Cannulated screws ( $n=22)$} & Lateral and medial approaches & $11 / 50$ \\
\hline & Lateral approach & $8 / 36$ \\
\hline & Anterior and lateral approaches & $1 / 5$ \\
\hline & $\begin{array}{l}\text { Lateral and medial approaches with additional subtalar } \\
\text { arthrodesis }\end{array}$ & $2 / 9$ \\
\hline \multirow{6}{*}{$\begin{array}{l}\text { Retrograde intramedullary } \\
\text { HAN rod (Synthes, Switzerland) } \\
(n=24)\end{array}$} & Lateral & $16 / 67$ \\
\hline & Lateral and medial approaches & $4 / 17$ \\
\hline & Lateral and anterior approaches & $1 / 4$ \\
\hline & Anterior approach & $1 / 4$ \\
\hline & Anterior and medial approach & $1 / 4$ \\
\hline & Medial approach & $1 / 4$ \\
\hline \multirow{2}{*}{$\begin{array}{l}\text { llizarov apparatus for external } \\
\text { fixation }(n=6)\end{array}$} & With resection of the joint surfaces & $5 / 83$ \\
\hline & Without resection of the joint surfaces & $1 / 17$ \\
\hline Wires $(n=4)$ & $\begin{array}{l}\text { Lateral approach with additional fixation of the external } \\
\text { ankle to the talar bone by a screw }\end{array}$ & $4 / 100$ \\
\hline
\end{tabular}

$\mathrm{N}$ o t e. The shown percentage is of the total number of arthrodeses with the given fixator. 
obesity, stage III, in 6\% (BMI 40.0-49.54). Only 24\% of patients had normal body mass (BMI 18.0-24.7).

Four patients had diabetes mellitus, type II, two patients suffered heavy rheumatoid polyarthritis.

The leading causes for ankle joint arthrodesis were pain, significantly limited motions and support ability, prominent deformity. One patient with a high risk of developing infectious complication underwent closed arthrodesis without any resection of the joint surfaces.

Gender traits of the patients were taken into consideration: equines positioning of the foot was performed during arthrodesis for women, who had to wear heels at work or in connection with their social status.

The methods applied and fixators are presented in Table 2.

22 arthrodeses of 56 were performed using cannulated screws. In the majority of cases lateral and medial approaches were used by means of internal and external transmalleolar arthrotomy with the resection of the ankle cartilaginous surfaces. Then correcting osteotomy was performed both of the tibia and talus with the removal of the articular cartilage and subchondral layer. The foot was set in a physiologically favorable position and fixed by the two crossing cannulated screws, introduced over the guidewires through the tibia to the talus. Lateral malleolus was fixed by one or two screws to the tibia, stabilizing the zone of arthrodesis (Figure 1). Seven arthrodeses with resection of the articular surfaces were performed using one transmalleolar lateral approach with the following fixation of the lateral malleolus by cortical screws to the tibial and talar bones. One arthrodesis was approached from the anterior side, as placement of endoprosthesis had initially been planned. In this case articular surfaces were resected, osteotomy of the lateral malleolus and fixation by two crossing screws were performed.

Retrograde intramedullary HAN rods (Synthes, Switzerland) were Switzerland)
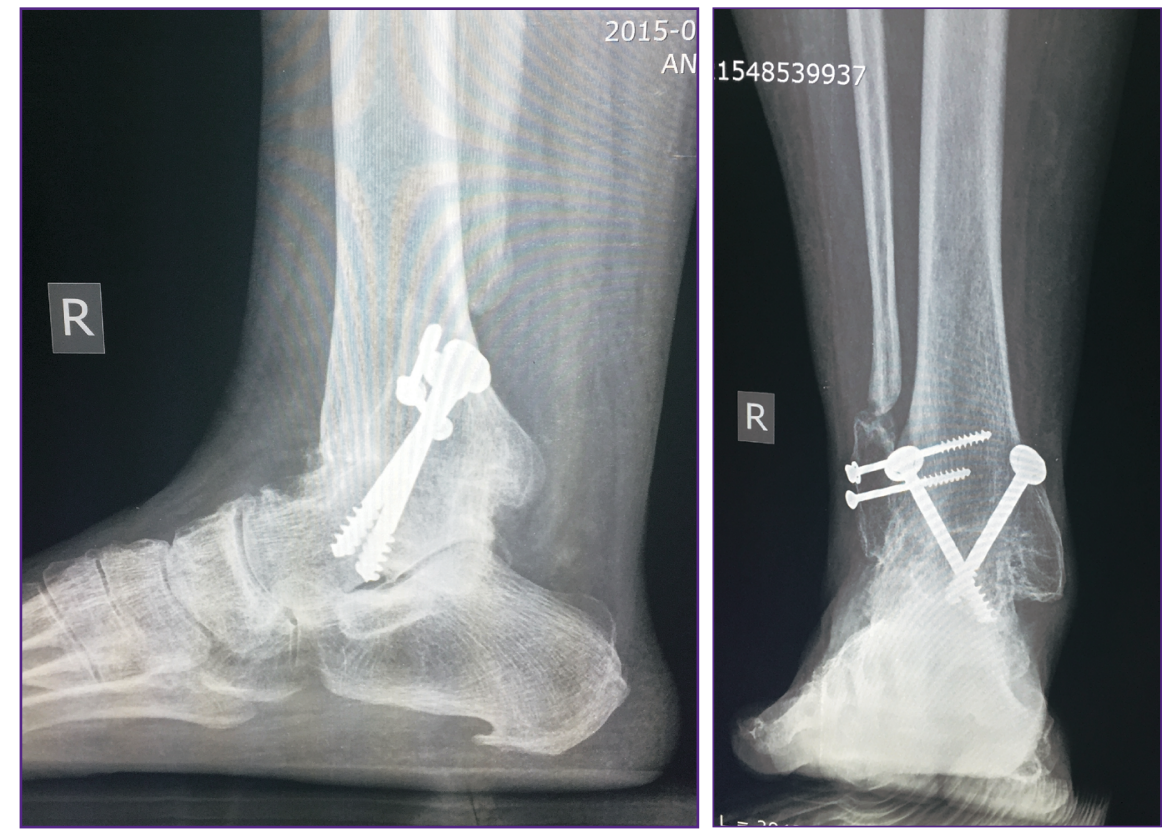

Figure 1. Radiographs of the ankle joint after arthrodesis by the screws
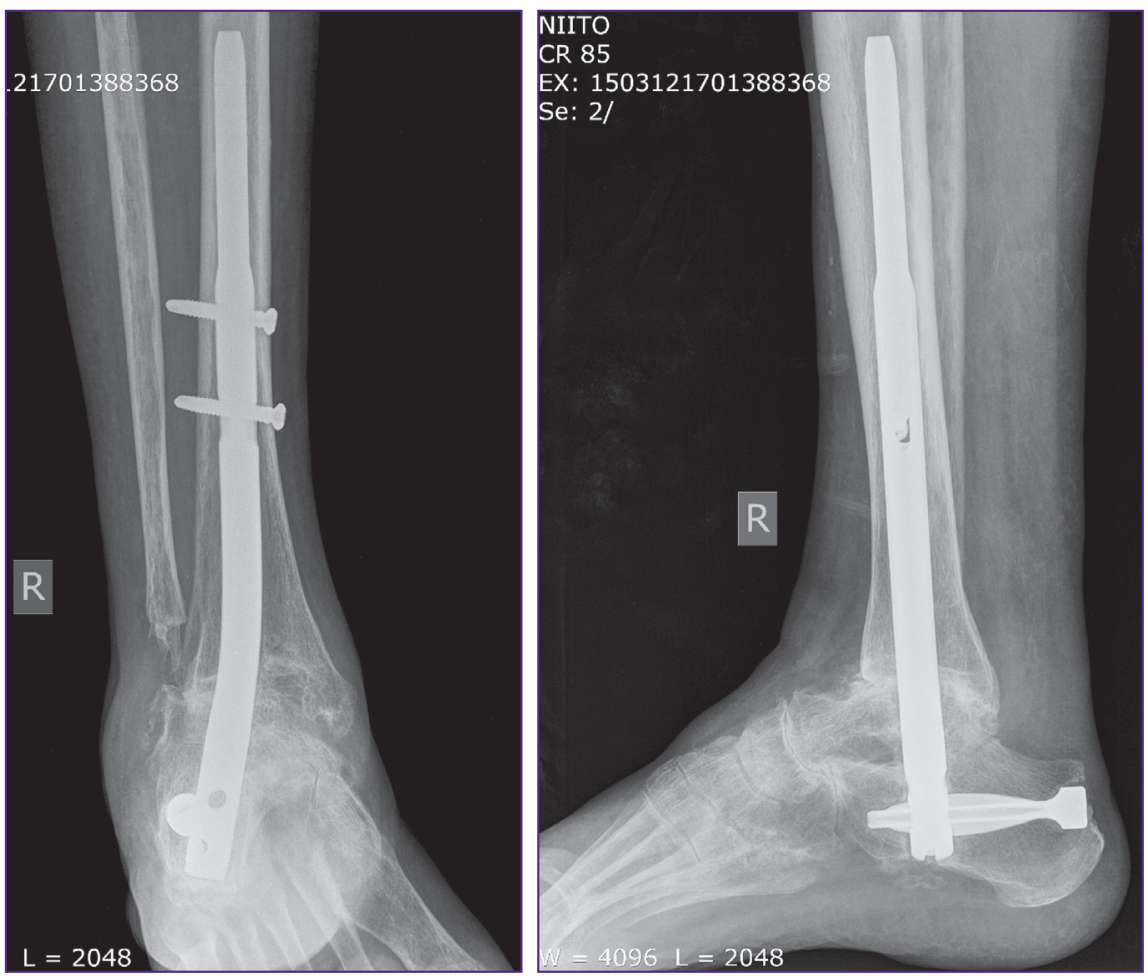

Figure 2. Radiographs of the ankle joint after arthrodesis by a HAN rod (Synthes, 


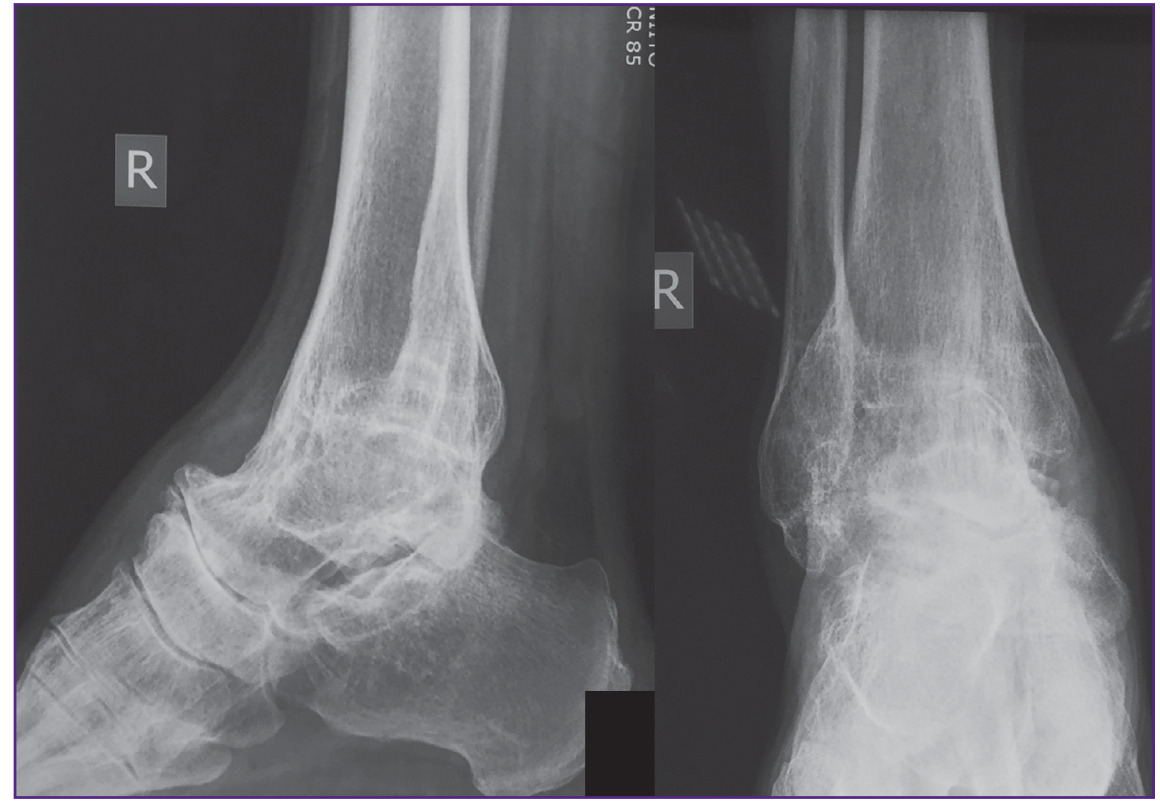

Figure 3. Radiographs of the ankle joint after arthrodesis by llizarov apparatus and talus, overlapping the zone of arthrodesis.

llizarov apparatuses for external fixation were used in six ankle fusions (Figure 3). One operation was a closed one without resection of articular surfaces due to unsatisfactory condition of the skin.

Patients underwent clinical and radiographic examination and questionnaire survey using international scale AOFAS, according to which a good result corresponds to 75-94 points, a satisfactory result equals to $51-74$ points, and unsatisfactory one is less than 50 points [43].

Results. The best results, i.e. the lower quantity (32\%) of ligamentous ankyloses found during clinical and radiographic examination (Table 3), and the greater quantity of good $(39 \%)$

(8 operations, 33\%) approaches were different, including combined ones, depending on the type and severity of deformation. Of them two patients were performed arthrodesis using lateral and medial transmalleolar approach with the removal of the lateral malleolus because of its marked deformity. Two patients were performed arthrodesis after unsuccessful replacement of the ankle joint. Ankle arthrodesis in both extremities was performed to a woman with an 8-month interval between the operations.

Three wires were used as transarticular fixators in 4 ankle fusions. Articular surfaces of the ankle were resected using the lateral approach with preliminary supramalleolar osteotomy, after that the foot was placed in physiologically favorable position. The lateral malleolus was secured by a cortical screw to the tibia and satisfactory (54\%) outcomes according to AOFAS (Table 4), were obtained in arthrodesis with screws and lateral and medial $(50 \%)$ or isolated lateral approaches $(36 \%)$.

The development of ligamentous ankylosis in arthrodesis performed by screws was mainly caused by: failure to observe doctor's recommendations in the postoperative period, and technical errors during the operation (insufficient removal of cartilaginous tissue, unrepaired deformation, fixation instability, arthrodesis in non-physiological position). Bone ankylosis with a good clinical result (75 and 79 scores according to AOFAS) was formed in two patients, who underwent additionally subtalar arthrodesis by the screws. Among the patients with cartilaginous ankylosis obesity (BMl>30) was noted only in two (Table 5).

Table 3

Results of clinical and radiographic examination of patients after ankle joint arthrodesis (abs. number/\%)

\begin{tabular}{|c|c|c|c|c|c|}
\hline Type of fixator & $\begin{array}{l}\text { Quantity } \\
\text { of bone } \\
\text { ankyloses }\end{array}$ & $\begin{array}{c}\text { Quantity } \\
\text { of ligamentous } \\
\text { ankyloses }\end{array}$ & $\begin{array}{l}\text { Quantity of ligamentous } \\
\text { ankyloses } \\
\text { with the development } \\
\text { of infectious complications } \\
\text { entailing fixator removal }\end{array}$ & $\begin{array}{c}\text { Quantity of bone } \\
\text { ankyloses } \\
\text { with a prominent deformity } \\
\text { of the ankle joint }\end{array}$ & $\begin{array}{l}\text { Quantity } \\
\text { of ligamentous } \\
\text { ankyloses ended } \\
\text { in amputation }\end{array}$ \\
\hline Cannulated screws & $15 / 68$ & $7 / 32$ & - & - & - \\
\hline $\begin{array}{l}\text { Retrograde intramedullary } \\
\text { HAN rod (Synthes) }\end{array}$ & $15 / 62$ & $3 / 13$ & $3 / 13$ & $1 / 4$ & $2 / 8$ \\
\hline Ilizarov apparatus & $4 / 67$ & $2 / 33$ & - & - & - \\
\hline Wires & $1 / 25$ & $2 / 50$ & $1 / 25$ & - & - \\
\hline Total & $35 / 62$ & $14 / 25$ & $4 / 7$ & $1 / 2$ & $2 / 4$ \\
\hline
\end{tabular}

$\mathrm{N}$ o t e. The shown percentage is of the total number of ankyloses with the given fixator. 
Table 4

Results of scoring the patients after ankle joint arthrodesis according to AOFAS scale (abs. number/\%)

\begin{tabular}{lcccc}
\hline \multicolumn{1}{|c}{ Type of fixator } & Good result & Satisfactory result & Unsatisfactory result & $\begin{array}{c}\text { Number } \\
\text { of patients }\end{array}$ \\
\hline Cannulated screws & $5 / 39$ & $7 / 54$ & $1 / 7$ & 13 \\
\hline HAN rod & $1 / 10$ & $6 / 60$ & $3 / 30$ & 10 \\
\hline llizarov apparatus & $2 / 40$ & $2 / 40$ & $1 / 20$ & 5 \\
\hline Wires & 0 & $1 / 33$ & $2 / 67$ & 3 \\
\hline Total & $8 / 26$ & $16 / 52$ & $7 / 22$ & 31 \\
\hline
\end{tabular}

$\mathrm{N}$ o t e. The shown percentage is of the total number of ankyloses with the given fixator.

Table 5

Types of fixators in patients with obesity (BMI >30)

\begin{tabular}{lcc}
\hline Type of fixator & $\begin{array}{c}\text { Number } \\
\text { of patients } \\
\text { with obesity }\end{array}$ & $\begin{array}{c}\text { Number of ligamentous } \\
\text { ankyloses in patients } \\
\text { with obesity }\end{array}$ \\
\hline Cannulated screws & 9 & 2 \\
\hline HAN rod & 6 & 1 \\
\hline Ilizarov apparatus & 4 & 1 \\
\hline Wires & 1 & 1 \\
\hline Total & 20 & 5 \\
\hline
\end{tabular}

When retrograde intramedullary HAN rods were used for ankle fusion, the number of bone ankiloses were slightly lower compared to the screws and amounted to $62 \%$. However, the quantity of postoperative complications was much higher and equaled to $38 \%$ (See Table 3). The survey according to AOFAS showed satisfactory results in $60 \%$ of cases (6 patients). Unsatisfied outcomes were noted in 3 patients, 2 of them underwent amputation at the level of the upper third of the tibia for severe deformation of the ankle joint and foot with decompensating neurovascular disorders without any further opportunity to restore supporting ability. In one patient rearthrodesis by the apparatus for external fixation was required due to the incorrect foot position in the formed bone ankylosis. Lateral approach was most frequently used (67\%). Among the patients with ligamentous ankylosis obesity $(\mathrm{BMI}>30)$ was observed only in one patient.

When wires were used in arthrodesis, complications in the postoperative period developed in $75 \%$ of cases (See Table 3), which were connected with insufficient stability of the joint for the formation of bone ankylosis. Among the patients with ligamentous ankylosis only one suffered obesity (BMI>30).

Bone ankylosis formed in $67 \%$ of cases when llizarov apparatus for external fixation was used in arthrodesis. The quantity of good and satisfactory results measured according to AOFAS amounted to $80 \%$. In one patient, who was performed closed arthrodesis without resection of the articular surfaces, ligamentous ankylosis was formed with marked pains. Among the patients with ligamentous ankylosis only one suffered obesity (BMI >30).

Three main signs are measured by the AOFAS clinical rating scale: pain, function, and foot position.

Pain is the main characteristic in this assessment (40 points), as its arrest is the chief indicator of a good outcome after ankle arthrodesis. Complete absence of pain was noted in patients after arthrodesis by screws and a HAN rod (36 and $25 \%$, respectively). When apparatuses of external fixation and wires were used, none of the patients experienced full arrest of the pain syndrome, despite the formation of the bone ankle ankylosis; all patients complained of the moderately intensive periodic pain during supporting loads, and $45 \%$ of patients required analgesics intake. A severe, almost constant pain both in walking and at rest was noted only in 2 patients in the group with arthrodesis by a HAN rod, despite the formed bone ankylosis. In one patient it was due to the intraoperative technical error (the wrong point of the rod introduction resulted in the valgus position, $15^{\circ}$, of the foot), the pain syndrome developed in the other patient because of the prominent joint arthrosis of the medial and anterior parts of the foot 2.5 years after the operation.

Functional activity was not limited and additional supporting means were not required in all groups in more than $50 \%$ of patients. The best results were achieved after arthrodesis by the apparatus for external fixation $(75 \%$ of patients did not require additional supporting means), as the period of follow up for this group of patients prevailed and amounted to 10-15 years $(12.0 \pm 1.3$ ) (in arthrodesis with screws $-2.1 \pm 0.2$, with a HAN rod $-2.3 \pm 0.4$, and with wires $-3.1 \pm 0.5)$. It may be explained, in our opinion, by the compensatory adaptation of the adjacent joints during a long postoperative period.

Maximal walking distance is a sign, which is difficult to evaluate, since it depends on the patient's age, the need for long-distance walks, and concomitant pathology 
including other joint diseases. An average walking distance in our study ranged from 4 to $6 \mathrm{~km}$ (in $49 \%$ of patients) and from 1 to $3 \mathrm{~km}$ (in $41 \%$ of patients) in each group.

In the majority of patients (over 63\%) moderately difficult walking was noted over uneven surface with an irregular coating (hillocks, stones, stairs, slopes), which was not related to the fixation technique.

The indicator of abnormal gait (limping) was also very individual. It did not depend on the type of arthrodesis, but was caused primarily by an overweight, concomitant pathology, arthrosis of the adjacent joints, and the changed walking stereotype.

Supplementary external fixation in the form of orthosis, elastic bandage, special footwear were required for only one patient after arthrodesis by screws and for 3 patients after a HAN rod.

Foot positioning after arthrodesis by all methods of fixation was estimated to be good, or with a several degree deviation from the normal position.

Additional questioning on some other signs, not included into AOFAS, was carried out. Complaints of edema were not presented by $45 \%$ of patients after screw arthrodesis and $25 \%$ after HAN rod arthrodesis, in the rest groups edema occurred periodically, was insignificant after walking or by the end of the day.

Dependence of the required footwear (a flat sole, heels, running shoes and so on) on the type of arthrodesis was not found. However, the majority of patients (93\%), who underwent arthrodesis in the equinus position at $100^{\circ}$, used orthopedic footwear with heels, $65 \%$ used orthopedic insoles.

More than $55 \%$ of patients could squat resting over the whole foot independent on the arthrodesis type. The rest of the patients were not able to do it, probably because the compensatory stereotype of movement or constitutional features had not yet been formed.

More than $36 \%$ of patients in all groups, except the arthrodesis by a HAN rod, could use the pedals of a car or bicycle. It was easier for the patients of all groups (over 75\%), except those with arthrodesis by the apparatus for external fixation, to go upstairs. While $75 \%$ of patients after arthrodesis by Ilizarov apparatus preferred to go downstairs, that is thought to be connected with the limited motion in the compensatory joints due to formed arthrosis caused by their prolonged hyperfunction.

Discussion. The complex assessment of the results obtained allowed us to work out a modern concept of ankle joint arthrodesis for posttraumatic deforming crusarthrosis, grade III-IV.

Examining the patients it is necessary to use clinical and radiographic methods, as well as the analysis of separate signs, characterizing various features of everyday activity (walk duration, walking over various kinds of surfaces, etc.).

The most commonly used AOFAS rating scale, in our opinion, does not reflect the most important spectrum of patients' life activity indices. Such its parameters as abnormal gait, maximal walking distance, mobility and stability of the foot and posterior parts, are considered by us insufficiently informative for the evaluation of the outcomes of ankle arthrodesis, and we suggest adding some indices, characterizing the life quality of patients of different professions, the every-day activity level and psychological motivation for adequate rehabilitation (ability to stand on tiptoe, to go in for sports, e.g. jogging or fast walking, to use the car o bicycle pedals and others).

Unsatisfied radiographic findings do not always lead to poor clinical results: $56 \%$ of patients with ligamentous ankylosis have good or satisfactory results according to AOFAS (mild pains in prolonged walking, movements without additional supporting tools, absence of evident limping).

The best radiographic, clinical and functional results (an average score 70.5 according to AOFAS and the less quantity of ligamentous ankylosis) are achieved with AO screws, which is likely to be associated with a strong fixation and primary compression stability. Follow up results after arthrodesis by a HAN rod showed a somewhat worse outcome measured by AOFAS (an average score 55.6) and a weaker predisposition to bone ankylosis. Insufficient primary compression in the zone of arthrodesis and evident impairment of talus blood supply, while placing this massive fixator, are believed to be the cause of this condition.

Application of Ilizarov apparatus shows reliability of fixation and compression, a great number of bone ankyloses $(66 \%)$ and a large quantity of good and satisfactory results according to AOFAS (80\%). However, the necessity of continuous control over the soft tissues around the wires, long-term inconvenience for the patient limits the use of this fixator in arthrodesis.

Arthrodesis by wires shows the greatest number of ligamentous ankylosis development and absence of good results according to AOFAS, as it does not provide compression and sufficient stability in the arthrodesis zone. It is recommended, if other methods and fixators cannot be applied.

The assessment of arthrodesis outcomes in overweight and obese patients did not reveal any relation between bone or ligamentous ankylosis and BMI. Only in $25 \%$ of patients with ligamentous ankylosis BMI $>25$ was found, and in $90 \%$ of them intraoperative technical errors were made (incomplete removal of axial deformity, absence of sufficient stability and compression in the zone of arthrodesis). The infectious complications observed in such patients do not also depend on this index and are likely connected with other reasons (a severe form of rheumatoid arthritis, diabetes mellitus, instability of initial fixation by wires).

Conclusion. The worked out concept of modern arthrodesis consists in the choice of ankle arthrodesis 
method and the type of a fixing implant, that must depend not only on the type of deformity, but on the patient's age, gender traits, diseases contributing to the development of unfavorable treatment results (a severe form of rheumatoid arthritis, diabetes mellitus, impaired blood supply of the distal parts of the lower limbs). The best clinical and functional results are connected with the method of fixation providing primary stability, and with regenerative and adaptive capabilities of patients, availability of compensatory movement stereotype, constitutional peculiarities, absence of degenerative diseases of the large joints of the lower limbs and the joints of the posterior, medial and anterior parts of the foot. The most optimal state-of-the-art implant for arthrodesis is a transverse fixation by screws, providing the greatest strength and good primary compression, if there is no marked disorder of blood supply of the articular bones and radical removal of the cartilaginous tissue.

Study Funding and Conflicts of Interest. The work was not funded by any source, and there are no conflicts of interest related to this study.

\section{References}

1. Udartsev Ye.Yu., Chantsev A.V., Raspopova Ye.A. Differentiated pathogenetic approach to the selection of rehabilitation facilities for the patients with the posttraumatic knee and ankle osteoarthrosis. Travmatologiya $i$ ortopediya Rossii 2009; 3(53): 20-27.

2. Arkhipov S.V., Lychagin A.V. Modern aspects of treatment of post-traumatic ankle joint arthrosis deformans. Vestnik travmatologii $i$ ortopedii im. N.N. Priorova 2000; 4: 64-67.

3. Omel'chenko T.N. Fractures of the ankles and rapidly progressing osteoarthrosis of the ankle joint: prevention and treatment. Ortopediya, travmatologiya i protezirovanie 2013; 4(593): 35-40.

4. Yaremenko D.A., Ershov D.V., Yaremenko O.D. Clinical picture, diagnosis and surgical treatment of old injuries of tibiofibular syndesmosis (review). Ortopediya, travmatologiya $i$ protezirovanie 2012; 4(589): 129-136.

5. Rolik O.V., Zasadnyuk I.A. Non-union of long bones (analysis, risk factors, medical tactic). Ortopediya, travmatologiya i protezirovanie 2005; 2: 61-65.

6. Travmatologiya $i$ ortopediya. T. 3 [Traumatology and orthopedics. Vol. 3]. Pod red. Kornilova N.V., Gryaznukhina E.G. [Kornilov N.V., Gryaznukhin E.G. (editors)]. Saint Petersburg; 2006.

7. Glazebrook M., Daniels T., Younger A., Foote C.J., Penner M., Wing K., Lau J., Leighton R., Dunbar M. Comparison of health-related quality of life between patients with end-stage ankle and hip arthrosis. $J$ Bone Joint Surg Am 2008; 90(3): 499-505, http://dx.doi.org/10.2106/JBJS.F.01299.

8. Segal A.D., Shofer J., Hahn M.E. Functional limitations associated with end-stage ankle arthritis. J Bone Joint Surg Am 2012; 94(9): 777-783, http://dx.doi.org/10.2106/JBJS.K.01177.

9. Herscovici D., Sammarco G.J., Sammarco V.J., Scaduto J.M. Pantalar arthrodesis for post-traumatic arthritis and diabetic neuroarthropathy of the ankle and hindfoot. Foot
Ankle Int 2011; 32(6): 581-588, http://dx.doi.org/10.3113/ FAl.2011.0581.

10. Horst F., Nunley J.A. 2nd. Ankle arthrodesis. J Surg Orthop Adv 2004; 13(2): 81-90.

11. Olson K.M., Dairyko G.H. Jr., Toolan B.C. Salvage of chronic instability of the syndesmosis with distal tibiofibular arthrodesis: functional and radiographic results. J Bone Joint Surg Am 2011; 93(1): 66-72, http://dx.doi.org/10.2106/ JBJS.J.00030.

12. Stoyanov A.V., Emelyanov V.G., Pliev D.G., Mikhaylov K.S. Ankle joint replacement. Travmatologiya $i$ ortopediya Rossii 2011; 1(59): 144-152.

13. Shesternya N.A., Ivannikov S.V., Lazarev A.F., Morozov A.K. Povrezhdeniya v zone golenostopnogo sustava [Damages in the zone of the ankle joint]. Moscow; 2011.

14. Yaremenko D.A., Baburkina E.P., Kishkar' A.V. Arthrodesis in aftereffects of ankle joint trauma complications. Ortopediya, travmatologiya i protezirovanie 2000; 3: 77-81.

15. Slivkov K., Brijan' L., Davydov D., Kerimov A. Prevention of infectious complications in the ankle joint arthrodesis. Infektsii v khirurgii 2013; 11(2): 12-13.

16. Ahmad J., Raikin S.M. Ankle arthrodesis: the simple and the complex. Foot Ankle Clin 2008; 13(3): 381-400, http:// dx.doi.org/10.1016/j.fcl.2008.04.007.

17. Saltzman C.L., Kadoko R.G., Suh J.S. Treatment of isolated ankle osteoarthritis with arthrodesis or the total ankle replacement: a comparison of early outcomes. Clin Orthop Surg 2010; 2(1): 1-7, http://dx.doi.org/10.4055/cios.2010.2.1.1.

18. Schuh R., Hofstaetter J., Krismer M., Bevoni R., Windhager R., Trnka H.J. Total ankle arthroplasty versus ankle arthrodesis. Comparison of sports, recreational activities and functional outcome. Int Orthop 2012; 36(6): 1207-1214, http:// dx.doi.org/10.1007/s00264-011-1455-8.

19. Trouillier H., Hänsel L., Schaff P., Rosemeyer B., Refior H.J. Long-term results after ankle arthrodesis: clinical, radiological, gait analytical aspects. Foot Ankle Int 2002; 23(12): 1081-1090.

20. Fuchs S., Sandmann C., Skwara A., Chylarecki C. Quality of life 20 years after arthrodesis of the ankle. A study of adjacent joints. J Bone Joint Surg Br 2003; 85(7): 994-998, http://dx.doi.org/10.1302/0301-620x.85b7.13984.

21. Guo C., Yan Z., Barfield W.R., Hartsock L.A. Ankle arthrodesis using anatomically contoured anterior plate. Foot Ankle Int 2010; 31(6): 492-498, http://dx.doi.org/10.3113/ FAI.2010.0492.

22. Herscovici D.Jr., Scaduto J.M. Use of the reamerirrigator-aspirator technique to obtain autograft for ankle and hindfoot arthrodesis. J Bone Joint Surg Br 2012; 94(1): 75-79, http://dx.doi.org/10.1302/0301-620X.94B1.27690.

23. Raikin S.M. Arthrodesis of the ankle: arthroscopic, miniopen, and open techniques. Foot Ankle Clin 2003; 8(2): 347359, http://dx.doi.org/10.1016/s1083-7515(03)00014-7.

24. Thordarson D.B. Fusion in posttraumatic foot and ankle reconstruction. J Am Acad Orthop Surg 2004; 12(5): 322-333, http://dx.doi.org/10.5435/00124635-200409000-00007.

25. Hendrickx R.P., Stufkens S.A., de Bruijn E.E., Sierevelt I.N., van Dijk C.N., Kerkhoffs G.M. Medium- to longterm outcome of ankle arthrodesis. Foot Ankle Int 2011; 32(10): 940-947, http://dx.doi.org/10.3113/fai.2011.0940.

26. Hoover J.R., Santrock R.D., James W.C. 3rd. Ankle fusion stability: a biomechanical comparison of external versus internal fixation. Orthopedics 2011; 34(4): 272, http://dx.doi. org/10.3928/01477447-20110228-04. 
27. Akra G.A., Middleton A., Adedapo A.O., Port A., Finn P. Outcome of ankle arthrodesis using a transfibular approach. $J$ Foot Ankle Surg 2010; 49(6): 508-512, http://dx.doi. org/10.1053/j.jfas.2010.07.004.

28. Richter M., Evers J., Waehnert D., DeOrio J.K., Pinzur M., Schulze M., Zech S., Ochman S. Biomechanical comparison of stability of tibiotalocalcaneal arthrodesis with two different intramedullary retrograde nails. Foot Ankle Surg 2014; 20(1): 14-19, http://dx.doi.org/10.1016/j.fas.2013.08.003.

29. Thomas R.L., Sathe V., Habib S.I. The use of intramedullary nails in tibiotalocalcaneal arthrodesis. J Am Acad Orthop Surg 2012; 20(1): 1-7, http://dx.doi. org/10.5435/00124635-201201000-00001.

30. Lui T.H. Tibiotalocalcaneal arthrodesis with combined retrograde intramedullary nail and lateral L-plate. J Foot Ankle Surg 2012; 51(5): 693-695, http://dx.doi.org/10.1053/j. jfas.2012.05.012.

31. Berkowitz M.J., Clare M.P., Walling A.K., Sanders R. Salvage of failed total ankle arthroplasty with fusion using structural allograft and internal fixation. Foot Ankle Int 2011; 32(5): S493-S502, http://dx.doi.org/10.3113/FAl.2011.0493.

32. Nielsen K.K., Linde F., Jensen N.C. The outcome of arthroscopic and open surgery ankle arthrodesis: a comparative retrospective study on 107 patients. Foot Ankle Surg 2008; 14(3): 153-157, http://dx.doi.org/10.1016/j. fas.2008.01.003.

33. Stone J.W. Arthroscopic ankle arthrodesis. Foot Ankle Clin 2006; 11(2): 361-368, http://dx.doi.org/10.1016/j. fcl.2006.03.007.

34. Cottino U., Collo G., Morino L., Cosentino A., Gallina V., Deregibus M., Tellini A. Arthroscopic ankle arthrodesis: a review. Curr Rev Musculoskelet Med 2012; 5(2): 151-155, http://dx.doi.org/10.1007/s12178-012-9119-x.

35. Ogut T., Glisson R.R., Chuckpaiwong B., Le I.L.,
Easley M.E. External ring fixation versus screw fixation for ankle arthrodesis: a biomechanical comparison. Foot Ankle Int 2009; 30(4): 353-360, http://dx.doi.org/10.3113/FAI.2009.0353.

36. Salem K.H., Kinzl L., Schmelz A. Ankle arthrodesis using llizarov ring fixators: a review of 22 cases. Foot Ankle Int 2006; 27(10): 764-770.

37. Onodera T., Majima T., Kasahara Y., Takahashi D., Yamazaki S., Ando R., Minami A. Outcome of transfibular ankle arthrodesis with Ilizarov apparatus. Foot Ankle Int 2012; 33(11): 964-968, http://dx.doi.org/10.3113/fai.2012.0964.

38. Khanfour A.A. Versatility of Ilizarov technique in difficult cases of ankle arthrodesis and review of literature. Foot Ankle Surg 2013; 19(1): 42-47, http://dx.doi.org/10.1016/j. fas.2012.10.001.

39. Werner B.C., Burrus M.T., Looney A.M., Park J.S., Perumal V., Cooper M.T. Obesity is associated with increased complications after operative management of end-stage ankle arthritis. Foot Ankle Int 2015; 36(8): 863-970, http://dx.doi. org/10.1177/1071100715576569.

40. Strasser N.L., Turner N.S. Functional outcomes after ankle arthrodesis in elderly patients. Foot Ankle Int 2012; 33(9): 699-703, http://dx.doi.org/10.3113/fai.2012.0699.

41. Wilson J.A., Clark J.J. Obesity: impediment to postsurgical wound healing. Adv Skin Wound Care 2004; 17(8): 426-435, http://dx.doi.org/10.1097/00129334$200410000-00013$.

42. Yuan K., Chen H.L. Obesity and surgical site infections risk in orthopedics: a meta-analysis. Int J Surg 2013; 11(5): 383-388, http://dx.doi.org/10.1016/j.ijsu.2013.02.018.

43. Mashkov V.M., Nesenyuk E.L., Sorokin E.P., Bezrodnaya N.V., Shakhmatenko I.E. Surgical correction of hallux valgus in patients with transverse flatfoot and deforming arthrosis of the first metatarsophalangeal joint. Travmatologiya i ortopediya Rossii 2013; 1(67): 72-78. 